\title{
CONSTRUINDO A AUTONOMIA MORAL NA ESCOLA: os conflitos interpessoais e a aprendizagem dos valores
}

\author{
Building moral autonomy in school: \\ interpersonal conflicts and the learning of values
}

\section{Telma Pileggi Vinha ${ }^{[a]}$, Luciene Regina Paulino Tognetta ${ }^{[b]}$}

[alD outora em educação, Professora da Faculdade de E ducação da Universidade Estadual de Campinas (Unicamp), Campinas, SP - Brasil, e-mail: telmavinha@uol.com.br

${ }^{[b]}$ D outorado em Psicologia Escolar e do D esenvolvimento Humano, Professora da Faculdade deEducação da UniversidadeEstadual de Campinas (Unicamp), Campinas, São Paulo - Brasil, e-mail: lrpaulino@ uol.com.br

\section{Resumo}

A partir de pesquisas que investigaram se 0 ambiente escolar influencia o desenvolvimento moral dos alunos e a maneira com a qual eles se relacionam e resolvem seus conflitos interpessoais, propõe-se uma reflexão, fundamentada na teoria construtivista, sobre a forma como os conflitos têm sido resolvidos na escola em duas perspectivas (tradicional e construtivista) e uma análise das consequências destes na formação moral dos alunos. Inicialmente é apresentado um breve quadro teórico que fundamenta essas investigações, descrevendo o desenvolvimento moral segundo a teoria de Jean Piaget e outros pesquisadores que compartilham dessa concepção, e são estabelecidas

Rev. Diálogo Educ., Curitiba, v. 9, n. 28, p. 525-540, set./ dez. 2009 
algumas reflexões so bre o ambiente sociomoral da escola e a construção da autorregulação. Constata-se que, apesar de os educadores afirmarem que pretendem favorecer a formação de pessoas autônomas que vivam relações mais justas, respeitosas e solidárias, nem sempre conseguem fazer com que as crianças e os jovens pautem suas ações em princípios morais e autorregulem seus comportamentos. Em seguida, são apresentados os principais processos utilizados para intervir nas situações de conflitos interpessoais tanto pelos educadores que possuem uma perspectiva tradicional quanto na construtivista, compreendendo que estes transmitem mensagens que dizem respeito à moralidade. $0 \mathrm{~s}$ resultados encontrados indicam que, apesar dos professores terem objetivos comuns, o processo empregado nas escolas mais tradicionais favorece a manutenção de altos níveis de heteronomia em seus alunos. Constatou-se ainda que, por causa da concepção de que os conflitos são naturais nas relações e podem ser oportunidades para trabalhar os valores e regras e ao emprego de intervenções mais coerentes com 0 processo de construção da moralidade, tais intervenções contribuíram mais efetivamente para a melhoria das relações interpessoais e para 0 desenvolvimento da autorregulação.

Palavras-chave: Conflito interpessoal. Desenvolvimento moral. Construtivismo (Educação). Valores.

\begin{abstract}
Based on previous research that investigated if the environment in schools influences the moral development of students and the means by which they interrelate with each other and solve interpersonal conflicts, a contemplation is proposed, founded on Piaget's constructivist theory, about how conflicts have been dealt with in schools under two perspectives (traditional and constructivist), and an analyses of its consequences to the moral development of the students. Primarily, some ideas about the construction of the selfregulation and the sociomoral environment in schools are exposed. Studies indicate that despite the educators display their intention of favoring the development of autonomous human beings who could live fairer, more compassionate and more respectful relations, they not always are successfully capable of persuading the children and adolescents to act under moral principles or self-regulate their
\end{abstract}

Rev. Diálogo Educ., Curitiba, v. 9, n. 28, p. 525-540, set./ dez. 2009 
behaviors. Subsequently, the main processes utilized either by the educators who follow a traditional perspective as well as by the constructivists to intervene in situations of interpersonal conflicts, considering that they convey messages regarding morality are exposed. The present results indicate that even though the teachers share the same aspirations, the process employed by the most conservative schools favors the continuance of higher levels of heteronomy within their students. Furthermore, due to the conception that conflicts are natural in relations and may even constitute opportunities to work with values and rules and also as a result of the employment of interventions more coherent with the process of building the morality, it has been observed that such interventions did contribute more effectively with the progress of self-regulation and enhancement of interpersonal relations.

Keywords: Interpersonal conflict. Moral development. Constructivism (Education). Values.

\section{A construção da autonomia e o ambiente escolar}

O desenvolvimento da autonomia e de relações mais justas, respeitosas e solidárias são algumas das metas encontradas na maioria dos projetos pedagógicos das instituições escolares. Ao conversarmos com professores durante os cursos de formação, assessorias e nas pesquisas que realizamos, percebemos que, apesar de almejarem de fato esses objetivos, muitos não se sentem seguros sobre como esse desenvolvimento ocorre e como podem favorecê-lo no contexto educativo.

Jean Piaget (1932-1977) mostra-nos em seus estudos que o sujeito tem um papel ativo na construção dos valores, das normas de conduta. Há uma interação, isto é, um caminho de ida-e-volta, com o indivíduo atuando sobre o meio e o meio sobre ele, e não simplesmente a internalização pura desse ambiente. Na realidade, não é apenas um ou outro fator isolado (família, traços de personalidade, escola, amigos, meios de comunicação etc.), mas o conjunto deles que contribui nesse processo de construção de valores morais. Será durante a convivência diária, desde pequena, com 0 adulto, com seus pares, com as situações escolares, com os problemas com os quais se defronta, e também experimentando, agindo, que a criança irá construir seus valores, princípios e normas.

Rev. Diálogo Educ., Curitiba, v. 9, n. 28, p. 525-540, set./ dez. 2009 
A o relacionarmo-nos uns com os outros, é imprescindível a existência de regras que visam garantir a harmonia do convívio social. Aliás, as regras só existem em função da convivência humana e da necessidade de regulá-la. Contudo, para Piaget, o importante não são as normas em si, mas sim, o porquê as seguimos. Por exemplo, uma pessoa pode não furtar por medo de ser apanhada e outra porque os objetos não lhe pertencem. Ambas não furtaram, mas apesar de ser o mesmo ato, possuíam motivações bastante distintas... D esta forma, o valor moral de uma ação não está na mera obediência às regras determinadas socialmente, mas sim no princípio inerente a cada ação. É comum nas situações em que a criança mente, agride, furta, desrespeita, não compartilha algo ou é mal educada, que o adulto ensine-a a importância de não cometer tais atos. A questão é como o adulto o faz, pois este processo irá interferir nas razões pelas quais as normas serão legitimadas.

Piaget mostra que a criança nasce na anomia, isto é, há uma ausência total de regras. 0 bebê não sabe o que deve ou não ser feito, muito menos as regras da sociedade em que vive. Mais tarde, a criança começa a perceber a si mesma e aos outros, percebe também que há coisas que podem ou não ser feitas, ingressando no mundo da moral, das regras, tornando-se heterônoma, submetendo-se àquelas pessoas que detêm 0 poder. Na heteronomia, a criança já sabe que há coisas certas e erradas, mas são os adultos que as definem, isto é, as regras emanam dos mais velhos. Ela é naturalmente governada pelos outros e considera que o certo é obedecer às ordens das pesso as que são autoridade (os pais, professor ou outro adulto qualquer que respeite). A criança pequena ainda não compreende o sentido das regras, mas as obedece porque respeita a fonte delas (os pais e as pessoas significativas para ela). Além do amor que a leva a querer obedecer às ordens, a criança teme a própria autoridade em si, teme ainda a perda do afeto, da proteção, da confiança das pessoas que a amam. Há também o medo do castigo, da censura e de perder 0 cuidado. Nessa fase o controle é essencialmente externo. Há, portanto, uma aceitação de regras que são exteriores ao sujeito. 0 desenvolvimento moral foi bem sucedido quando, com o tempo, esse controle vai se tornando interno, isto é, um autocontrole, uma obediência às normas que não depende mais do olhar dos adultos ou de outras pessoas. É a moral autônoma.

É importante não confundir autonomia com individualismo ou liberdade para fazer o que bem entende, pois na autonomia é preciso coordenar os diferentes fatores relevantes para decidir agir da melhor maneira para todos os envolvidos, levando em consideração ao tomar

Rev. Diálogo Educ., Curitiba, v. 9, n. 28, p. 525-540, set./ dez. 2009 
decisões o princípio da equidade, ou seja, as diferenças, os direitos, os sentimentos, as perspectivas de si e as dos outros. $\mathrm{O}$ indivíduo que é autônomo segue regras morais que emergem dos sentimentos internos que o obrigam a considerar os outros além de si, havendo a reciprocidade. D esta forma, a fonte das regras não está mais nos outros, na comunidade ou em uma autoridade (como na moral heterônoma), mas no próprio indivíduo (autorregulação). La Taille (2001, p. 16) ressalta que "a pessoa é moralmente autônoma se, apesar das mudanças de contextos e da presença de pressões sociais ela permanece, na prática, fiel a seus valores e a seus princípios de ação. Assim, a pessoa heterônoma será aquela que muda de comportamento moral em diferentes contextos".

$\mathrm{Na}$ heteronomia, a obediência ao princípio ou regra não se mantém, pois depende de fatores exteriores, ou seja, a regulação é externa: em alguns contextos a pessoa segue determinados valores, e em outros não mais os segue. Por exemplo, se a pessoa corre 0 risco de ser punida não age de determinada forma, se não corre este risco, age; trata com respeito algumas pessoas que considera como "iguais" ou "superiores", mas outras não. Constata-se que se uma ação é movida apenas por fatores exteriores, ou seja, é motivada pelas circunstâncias, esta tende a desaparecer ou se modificar quando esses fatores externos também se modificarem.

Diversos estudos têm confirmado que o desenvolvimento moral está relacionado à qualidade das relações que se apresentam nos ambientes sociais nos quais a criança interage e, obviamente, essas relações não ocorrem apenas na família. A liás, é preciso que a criança possa ter experiências de vida social para aprender a viver em grupo e a escola é um local muito apropriado para essa vivência. Pesquisas nacionais e internacionais (ARAÚJO , 1993; BAGAT, 1986; DEVRIES; ZAN, 1998; TO G NETTA, 2003; VINHA, 2000, 2003) indicam que as escolas inevitavelmente influenciam de modo significativo na formação moral das crianças e jovens. Quanto mais o ambiente oferecido for cooperativo, maior o desenvolvimento da autonomia, e; quanto mais autoritário, maiores os níveis de heteronomia.

Nos objetivos dos projetos pedagógicos de diferentes escolas analisados em nossas pesquisas não encontramos, de maneira explícita, a formação de pessoas obedientes, acríticas, submissas ou heterônomas. Não se pretende formar pessoas que sejam reguladas por mecanismos exteriores, seguindo ou não determinado princípio ou regra dependendo do contexto. Todavia, se os valores morais não fizerem parte da identidade do sujeito, da sua perspectiva ética, não estiverem alicerçados numa convicção pessoal, os

Rev. Diálogo Educ., Curitiba, v. 9, n. 28, p. 525-540, set./ dez. 2009 
jovens não seguirão as regras e os princípios, movidos pelo sentimento de obrigação, mas sim por interesse ou submissão acrítica (a ação moral é decorrente do sentimento de obrigação, da autorregulação). 0 que ocorre frequentemente é que, no cotidiano da escola e das famílias, os adultos utilizam procedimentos que levam as crianças e jovens a se submeterem a essas normas porque uma autoridade (pais, professores etc.) assim o quer ou "sabe o queé melhor para elas", atuando, por conseguinte, por caminhos que promovem mais a obediência do que a autonomia.

D este modo, encontra-se comumente nas escolas a imposição de regras tolas e desnecessárias ("não usar modismos"; "não conversar sem autorização do professor"); normas justificadas em nome da igualdade estrita (não da equidade) e da homogeneidade ("eu entendi que você não pode vir com a blusa do uniforme porque derrubou o achocolatado ao sair para o colégio e na casa de seu pai não havia outra blusa limpa, porém regra é regra e não posso abrir exceção, permitindo sua entrada na escola".) ou embasadas na mera obediência à autoridade ("não pode usar boné porque é a regra da escola"; "não fale assim porque senão contarei para seu pai"). Para que sejam cumpridas, são empregadas formas de legitimação por meio de procedimentos exteriores (receber uma recompensa, ser censurado ou punido) que somente reforçam a submissão e a obediência acrítica. Transmitem assim a ideia equivocada de que compreender e obedecer são coisas distintas. Tais procedimentos dificultam a compreensão das razões das regras, podendo, alongo prazo, apresentar efeitosindesejados, visto que a criança ou o jovem pode não construir suas próprias razões para seguir regras morais. Para haver a legitimação, é importante que o educador faça corresponder o cumprimento das normas a uma sensação de bem estar, de satisfação interna, de orgulho ao respeitá-las e também que promova a reflexão sobre as consequências naturais decorrentes do não cumprimento das mesmas, favorecendo o desenvolvimento do autorrespeito.

Enquanto a criança é pequena, heterônoma, esses procedimentos característicos de relações de respeito unilateral fazem com que seu comportamento seja controlável mesmo que as imposições sejam arbitrárias. Entretanto, conforme vão crescendo e desenvolvendose moralmente, esses mecanismos dificilmente funcionam. Então se observa o aumento do controle e da coerção, visando conseguir o "bom comportamento". A pesar de nobres intenções e belos discursos, muitos adultos preferem de fato a moral heterônoma e o respeito unilateral à moral autônoma e às relações de respeito mútuo, visto que estas são geradoras de conflitos e inquietações, exigem co erência e reciprocidade.

Rev. Diálogo Educ., Curitiba, v. 9, n. 28, p. 525-540, set./ dez. 2009 
Nessa complexa rede de interações na escola há um fenômeno que não pode ser esquecido pelos educadores: os conflitos ${ }^{1}$ interpessoais. Refletir sobre essa questão é necessário não somente pelo fato de os conflitos estarem sempre presentes, mas porque as intervenções decorrentes apresentam consequências significativas na construção dos valores e das regras, ou seja, na formação moral de nossas crianças e jovens. Mais do que inevitáveis, são necessários para que essa aprendizagem ocorra, como veremos a seguir.

\section{Os conflitos entre os alunos na escola}

Atualmente, muitos professores sentem-se impotentes e inseguros ao se depararem com problemas cada vez mais frequentes de indisciplina, de violência ou de conflitos, tais como agressões físicas e verbais, furtos, insultos, desobediência às normas, bullying, entre outros. A forte presença dessas situações nas instituições educativas é comprovada por inúmeros estudos (LA FÁBRICA D O BRASIL, 2001; NAKAYMA, 1999; VASCONCELOS, 2005). Um exemplo é uma recente pesquisa realizada por Biondi (2008) com base em questionários respondidos por diretores de todo o Brasil $\left(\right.$ Saeb $\left.^{2}\right)$ : a indisciplina por parte dos alunos é apontada como problema por $64 \%$ dos diretores das escolas estaduais, $54 \%$ das municipais e $47 \%$ das instituições particulares. Fante (2003) também constatou que $47 \%$ dos professores dedicam entre $21 \%$ e $40 \%$ do seu dia escolar aos problemas de conflitos entre alunos. Em uma investigação sobre conflitos em escolas públicas e privadas de São Paulo, Leme (2006) encontrou que 52\% dos alunos da $6^{\underline{a}}$ e 46,9\% de 8aㅗ séries concordaram com a afirmação de que os conflitos aumentaram nos últimos anos. Os conflitos entre os alunos foram apontados por 85,5\% dos diretores paulistas com um aspecto muito importante para garantir o bom funcionamento e convívio escolar.

A pesar desses dados, alguns educadores parecem acreditar que os conflitos sejam ocorrências atípicas, quenão fazem parte do "currículo" nem de seu trabalho como professor e ainda concebem harmonia ou paz

1 O s conflitos, tanto os que ocorrem no interior do sujeito (cognitivos e morais) como entre os indivíduos (interpessoais), possuem um lugar relevante na teoria de Piaget. Por meio dos conflitos é que o processo de equilibração ou autorregulação é desencadeado. Ao utilizar simplesmente o vocábulo "conflito", estamos referindo-nos às interações entre as pessoas em que há algum desequilíbrio, questão primária desse trabalho.

2 Sistema de Avaliação da E ducação Básica.

Rev. Diálogo Educ., Curitiba, v. 9, n. 28, p. 525-540, set./ dez. 2009 
como ausência dos mesmos. D iante das brigas eatritos, esses educadores sentem-se inseguros e desconhecem como poderiam intervir de forma construtiva. O s educadores constatam, angustiados, que as brigas estão sendo resolvidas de forma cada vez mais violenta, mas sentem-se despreparados para realizarem intervenções diferentes de conter, punir, acusar, censurar, ameaçar, excluir, ou mesmo ignorar... Assim, acabam por educar moralmente agindo de maneira intuitiva e improvisada, pautando suas intervenções principalmente no senso comum.

Não obstante o tempo significativo dispensado a tais fenômenos pelo professor, raramente os cursos de formação estudam essas questões, deixando o futuro profissional em educação sem preparo para lidar com mais segurança ao defrontar-se com situações de conflitos que ocorrem em qualquer instituição educativa. Nas palavras de D ubet (1998, p. 230), "deveria haver cursos sobre a violência" dizia ele, "porque a gente deveria aprender a responder a isto como se aprende as matemáticas". E completa: "...é um absurdo. Esta formação deveria ser mais ágil, muito mais longa e muito menos ideológica."

Por conseguinte, acabam por ter reações impulsivas que, não raro, somente pioram o problema ou apenas contém o conflito no espaço escolar. Um exemplo seria o fato tão frequente de alguns alunos não agredirem dentro da escola, mas resolverem seus conflitos de forma violenta fora desta instituição; ou, ainda, utilizarem os meios de comunicação eletrônica como a internet para insultar, vingar-se ou intimidar. Essas situações também denotam a dificuldade de alguns jovens resolverem seus conflitos de forma não violenta, de chegarem a soluções que beneficiem pelo menos em parte os envolvidos e de expressarem seus sentimentos sem causar dano aos outros.

A concepção sobre os conflitos do professor e, consequentemente, 0 tipo de intervenção realizada por ele ao depararse com desavenças entre as crianças e jovens, interfere nas interações entre os alunos e no desenvolvimento socioafetivo dos mesmos, transmitindo mensagens que dizem respeito à moralidade. Em nossa pesquisa (TO GNETTA; VINHA, 2007; VINHA, 2003) comprovamos que, em geral, encontram-se duas grandes concepções sobre os conflitos interpessoais entre os educadores.

Em uma visão tradicional, os conflitos são vistos como sendo negativos e danosos ao bom andamento das relações entre os alunos. Tal concepção evidencia-se porque os esforços são, em geral, apontados para duas direções: a primeira delas seria evitá-los. Para isto, elaboramse regras e mais regras, controlam-se os comportamentos por meio de

Rev. Diálogo Educ., Curitiba, v. 9, n. 28, p. 525-540, set./ dez. 2009 
filmadoras ou através de vigilância sistemática dos alunos, trancam-se armários e salas de aula para evitar furtos, ameaçam, coagem.... A segunda direção ainda bastante prezada pela escola é a resolução rápida desses conflitos. D este modo, os educadores transferem o problema para a família ou especialista; dão as soluções prontas; utilizam mecanismos de contenção e punições; incentivam a delação; culpabilizam; admoestam; associam a obediência à regra ao temor da autoridade, ao medo da punição, da censura e da perda do afeto. São mecanismos de controle utilizados cotidianamente na escola, que "funcionam" temporariamente, mas que, além de reforçar a heteronomia, não raro contribuem para agravar o problema. Em longo prazo contribuem para formar jovens que possuem baixo índice de habilidade social, apresentando dificuldades para: emitir opiniões, argumentar e ouvir perspectivas diferentes sem sentir-se ameaçado; tomar decisões, expor e discutir seus sentimentos e coordenar perspectivas em ações efetivas. $\mathrm{Na}$ resolução de seus próprios conflitos empregam mecanismos ainda primitivos tais como as reações impulsivas, submissas ou agressivas; a não interação; as soluções unilaterais; a mentira... Como são privados de entender as justificativas para os valores e normas nas relações, esses jovens tendem a orientar suas ações de modo a receberem gratificações, evitarem castigos ou por mero conformismo, demonstrando que os valores morais foram pobremente interiorizados. 0 fato de fazer com que um comportamento não seja mais apresentado não significa que a criança ou jovem percebeu as consequências de tal ato e está aprendendo outras formas mais elaboradas de proceder; pode significar, simplesmente, que está sob controle por temor ou por interesse. Como nos recorda La Taille (1996, p. 10) "o aluno bem-comportado pode sê-lo por medo do castigo, por conformismo. Pouco importa: seu comportamento é tranquilo. Ele é disciplinado. Isto é desejável?". É a "educação do presente", que resolve, momentaneamente, o "problema" da escola.

Por certo, os conflitos são inevitáveis em salas de aula em que a interação social e 0 trabalho em equipe são valorizados. Obviamente, numa escola cujo ambiente sociomoral é cooperativo, ou seja, numa classe em que as interações sociais entre os pares são favorecidas, em que os alunos tomam decisões, realizam atividades em grupos, assumem pequenas responsabilidades, fazem escolhas etc., haverá bem mais situações de conflitos do que na escola tradicional, onde os alunos, em geral, interagem muito pouco uns com os outros, ficando a maior parte do tempo em silêncio, imóveis, copiando pontos, resolvendo folhas de exercícios, ouvindo as explicações do professor, cabendo ao docente resolver os

Rev. Diálogo Educ., Curitiba, v. 9, n. 28, p. 525-540, set./ dez. 2009 
problemas e tomar todas as decisões. Portanto, pode-se desconfiar de uma classe de alunos silenciosos e que possui poucas desavenças.

Já para o professor que possui uma perspectiva construtivista, os conflitos são compreendidos como naturais em qualquerrelação enecessários ao desenvolvimento da criança e do jovem. São vistos como oportunidades para que os valores e as regras sejam trabalhados, oferecendo "pistas" sobre o que precisam aprender. Por conseguinte, suas intervenções não enfatizam a resolução do conflito em si, o produto (como resolver?; mas sim o processo, ou seja, a forma com que os problemas serão enfrentados (o que eles poderão aprender com 0 ocorrido?). Os educadores que possuem esta concepção compreendem o conflito e sua resolução como partes importantes do "currículo" tanto quanto os outros conteúdos que devem ser trabalhados e não apenas o vendo como um problema a ser resolvido. D e acordo com essa perspectiva, ao invés de o professor gastar seu tempo e energia tentando preveni-los, deve-se aproveitá-los como oportunidades para auxiliar os alunos a reconhecerem as perspectivas próprias e as dos outros e aprenderem, aos poucos, como buscar soluções aceitáveis e respeitosas para todas as partes envolvidas. Ao agir assim, o educador demonstra reconheceraimportânciadedesenvolver-senas criançase jovens habilidades que os auxiliem naresolução deconflitosinterpessoais e, consequentemente, favorecer a formação de pessoas autônomas. Por exemplo: situações de mentira constituem-se em oportunidades para refletir sobre a necessidade da veracidade para manter o elo de confiança; circunstâncias em que há agressões físicas ou verbais entre os alunos podem ser aproveitadas para trabalhar o reconhecimento dos sentimentos e a resolução das desavenças de forma não violenta emais eficaz, por meio do diálogo; e assim por diante.

Piaget concebe o conflito, tanto o que ocorre no interior do sujeito como entre os indivíduos, como necessários ao desenvolvimento. Q uando ocorre um conflito na interação com o outro, o indivíduo é motivado por esse desequilíbrio a refletir sobre maneiras distintas de restabelecer a reciprocidade. Uma resolução de conflito considerada como positiva implica em um equilíbrio entre a capacidade de persuasão do outro e a satisfação de si mesmo, sendo necessário para isto operar considerando os sentimentos e perspectivas próprias e de uma outra pessoa (resolução cooperativa).

Por reconhecer a importância de favorecer a atividade no interior do sujeito, o professor que pauta suas intervenções nessa concepção reconhece que o conflito vivido pelos alunos não lhe pertence, assim sendo, não lhe cabe resolvê-lo retirando-os do mesmo. Frequentemente, o que ocorre é o contrário, ou seja, o professor retira

Rev. Diálogo Educ., Curitiba, v. 9, n. 28, p. 525-540, set./ dez. 2009 
os alunos do controle do próprio conflito ou problema, atribuindo a si próprio a resolução dessas situações vividas pelos alunos, dizendo-lhes 0 que deve ser feito (ou induzindo). Todavia, o fato de não solucionar por eles não é sinônimo de largá-los a própria sorte. Em situações de conflito, o educador poderá intervir explicitando o problema de tal forma que eles possam entender, ajudá-los a verbalizar seus sentimentos e desejos, promovendo uma interação, e auxiliá-los a escutar uns aos outros, convidando-os para colocar suas sugestões e propor soluções.

O professor auxilia o autoconhecimento quando ajuda as crianças e jovens a refletirem sobre seus sentimentos e tendências de reação, todavia, ele deve evitar tomar partido, falar pelos envolvidos ou propor a resolução, estimulando-os a descreverem por si próprios seus pontos de vista e sentimentos, favorecendo a coordenação dos mesmos. A escola deve ajudá-los a controlar seus impulsos, tornado-os aptos a refletir sobre as consequências de seus atos. Ressalta-se, todavia, que se os esforços do professor para mediar um atrito entre as crianças estão mostrando-se ineficientes porque elas estão bravas ou com raiva, ele pode pedir que se separem até se sentirem mais calmas, podendo escutar e falar.

Quando se tem a concepção de que harmonia não significa ausênciadeconflitos, pois estes são situações necessárias paraa aprendizagem e que lidar com eles não é algo "desviante" da função de educador, modificam-se, inclusive, os sentimentos diante dos mesmos. Compreendese que os problemas ou desavenças, por serem naturais em qualquer relação, devem ser administrados, não sofridos. A angústia ou a insegurança leva 0 sujeito a resolvê-los rapidamente, de forma improvisada, para "livrar-se" daquilo que gera esses sentimentos, assim, muitas vezes as intervenções são autoritárias e, não raro, desastrosas. Concebendo-os como inerentes às relações e necessários ao crescimento individual ou de um grupo, lida-se com os conflitos de forma mais serena, percebendo a necessidade de, muitas vezes, planejar o processo de resolução dos mesmos ("O que 0 conflito está indicando? 0 que os alunos precisam aprender? Como trabalhar essa questão?"), compreendendo que os procedimentos que serão empregados, as situações promovidas ou as regras que serão elaboradas não devem apenas atuar so bre as consequências de um problema, mas sim sobre as causas. Uma resolução considerada eficaz em um conflito é aquela que minimiza ou elimina as causas que o gerou.

Algumas pesquisas (LEME, 2004; PEREIRA, 1998; VINHA, 2003; VINYAMATA, 1999) indicam que o conflito pode ser um contexto construtivo, mas também pode ser destrutivo. N esse processo, a postura do professor fará grande diferença. Muitas vezes, a intervenção descuidada do

Rev. Diálogo Educ., Curitiba, v. 9, n. 28, p. 525-540, set./ dez. 2009 
adulto só faz com que os educandos tentem esconder o conflito e, outras vezes, a interferência do professor pode aumentar as hostilidades eacarretar maiores problemas. Daí a importância de se estudar e refletir com profundidade sobre esta dimensão das relações educativas tão necessária para a realização de um trabalho construtivo na escola, para minimizar a violência, para a melhoraria das interações sociais e para um maior favorecimento do desenvolvimento sociomoral de suas crianças e jovens.

\section{CONCLUSÕES}

Esse artigo pretendeu enfocar as intervenções em situações de conflitos interpessoais, todavia, sabemos que para favorecer 0 desenvolvimento da autonomia e de relações mais justas, respeitosas e solidárias é necessário to mar consciência de que a ética está presente nas mais diversas dimensõ es da escola, tais como: na relação da equipe de especialistas com os integrantes da instituição e também no trabalho docente, ou seja, na postura, nos juízos emitidos, na qualidade das relações que são estabelecidas, nas concepções e intervenções diante da indisciplina, do bullying, das infrações, dos conflitos... No tipo, quantidade, conteúdo, forma de elaboração e legitimação das regras; na maneira pela qual o conhecimento é concebido, trabalhado e avaliado; na relação e nas ações com a comunidade... Sabendo da importância de vivenciar a moral, mas de refletir, discutir e analisar as atitudes, além de se trabalhar conteúdos éticos de forma transversal e por projetos interdisciplinares, faz-se também necessário que os alunos (e adultos) tenham experiências vividas efetivamente com os valores morais, propiciando uma atmosfera sociomoral cooperativa no contexto educativo. E, é preciso, ainda, oferecer sistematicamente oportunidades para que a construção de valores morais aconteça, como um objeto do conhecimento que depende da tomada de consciência e, portanto, de momentos em que se possa pensar sobre o tema. Constata-se que raramente a educação apresenta ao aluno a moral como objeto de estudo e reflexão. D eseja-se que os alunos ajam moralmente, mas não se abrem espaços para que haja a reflexão sobre as ações, sobre os princípios e as normas, sobre os valores e sentimentos que nos movem... Portanto, considerando que a transmissão direta de conhecimentos é pouco eficaz para fazer com que os valores morais tornem-se centrais na personalidade, para a vivência democrática e cooperativa e para resolver problemas que requerem o desenvolvimento

Rev. Diálogo Educ., Curitiba, v. 9, n. 28, p. 525-540, set./ dez. 2009 
das dimensões cognitivas e afetivas, assim como de habilidades interpessoais, é preciso oferecer nas instituições educativas oportunidades frequentes para a realização de propostas de atividades sistematizadas que trabalhem os procedimentos da educação moral, tais como assembleias, ${ }^{3}$ discussão de dilemas, narrativas morais etc. Procedimentos estes que favoreçam a apropriação racional das normas e valores, 0 autoconhecimento e o conhecimento do outro, a identificação e expressão dos sentimentos, a aprendizagem de formas mais justas e eficazes de resolver conflitos e, consequentemente, 0 desenvolvimento da autonomia. ${ }^{4}$

Apesar de boas intenções e nobres objetivos dos educadores, infelizmente constata-se ainda que 0 ambiente sociomoral da maioria das escolas requer que os alunos sejam "bem comportados", tranquilos, submissos, passivos e obedientes em todos os aspectos, tanto nos relacionados à autonomia eà iniciativa, quanto ao pensamento reflexivo (D E VRIE S; ZAN , 1998). Todavia, uma educação pautada na submissão à autoridade e na o bediência acrítica às regras, sem a compreensão das necessidades ou dos princípios que as embasam, principalmente por conformismo e pelo temor de situações constrangedoras ou de punições, poderá modificar ações (externamente), mas dificilmente contribuirá para integrar ou situar os valores morais em um lugar central na personalidade, o que acarretaria em atitudes mais autônomas, isto é, coerentes com estes valores independentemente das pressões do meio exterior.

3 Segundo Puig (2000, p. 86), as assembleias são "o momento institucional da palavra e do diálogo. Momento em que o coletivo se reúne para refletir, tomar consciência de si mesmo e transformar o que seus membros consideram oportuno, de forma a melhorar os trabalhos e a convivência". É, portanto, um espaço para o exercício da cidadania onde as regras são elaboradas e reelaboradas constantemente, em que se discutem os conflitos e se negociam soluções, vivenciando a democracia e validando o respeito mútuo como princípio norteador das relações interpessoais. As assembleias de classe tratam de temáticas envolvendo especificamente determinada classe, tendo como objetivo regular e regulamentar a convivência e as relações interpessoais, assim como a resolução de conflitos por meio do diálogo. A periodicidade geralmente é semanal, em encontros de uma hora, ou quinzenal, com os mais velhos, com a duração de 90 minutos a 120 minutos. Esses momentos são inclusos no horário. São conduzidos inicialmente por um adulto, como o professor polivalente, o professor-conselheiro ou orientador, e, posteriormente, pelos próprios alunos-coordenadores (representantes eleitos que se revezam), sob orientação do adulto.

4 Para saber mais sobre os procedimentos da educação moral, expressão de sentimentos, assembleias e resolução de conflitos consultar: MO RENO ; SA STRE (2002); PUIG (2000, 2004); TOG NETTA (2003); TO G NETTA; VINHA (2007); VINHA (2000, 2003).

Rev. Diálogo Educ., Curitiba, v. 9, n. 28, p. 525-540, set./ dez. 2009 
A uxiliar na aprendizagem dos alunos e, ao mesmo tempo, favorecer seu desenvolvimento sociomoral podem aparentar serem problemas diferentes, mas não o são. Esta dissociação é equivocada, pois são sistemas solidários, visto que os eventos de desavenças pessoais e os de aprendizagem estão incorporados, fundem-se. A obtenção de relações equilibradas e satisfatórias (o que não significa que os conflitos estarão ausentes) não são frutos de um dom gratuito ou de desenvolvimento maturacional; mas sim, decorrentes de um processo de construção e aprendizagem. A criança ou jovem não irá aprender por si mesmo uma questão que é muito complexa e para a qual não foram previstas boas intervenções e oferecidas situações que lhe auxiliassem a aprender o que necessita. Porém, raramente se percebe a preo cupação das instituições escolares com as possibilidades pedagógicas dos conflitos, sendo que seus esforços nesta área estão mais voltados para conseguir um "bom comportamento" do aluno (muitas vezes por medo ou conformismo) e para a contenção do conflito do que para a aprendizagem.

\section{REFERÊNCIAS}

ARAÚJO, U. F. Um estudo da relação entre o ambiente cooperativo e o julgamento moral na criança. 1993. 194 f. D issertação (Mestrado em Educação) - Faculdade de Educação, Universidade Estadual de Campinas, Campinas, 1993.

BAGAT, M. P. Annotazzioni e riflessioni sull'autonomia morale. Attualitá. Psicologia, Roma, v. 1, n. 2, p. 49-56, 1986.

BIO ND I, R. Atributos escolares e o desempenho dos estudantes: uma análise em painel dos dados do Saeb. Brasília, MEC/ SEF, 2008. Disponível em: <http:/ / www.publicacoes.inep.gov.br/ detalhes.asp?pub=4321>.Acesso em: 12 mar. 2008.

DEVRIES, R.; ZAN, B. A ética na educação infantil. Porto Alegre: Artes Médicas, 1998.

DUBET, F. A formação dos indivíduos: a desinstitucionalização. Revista Contemporaneidade e Educação, São Paulo, v. 3, p. 27-33, 1998.

FANTE, C. Fenômeno bullying: estratégias de intervenção e prevenção da violência entre escolares. São José do Rio Preto, SP: Ativa, 2003.

Rev. Diálogo Educ., Curitiba, v. 9, n. 28, p. 525-540, set./ dez. 2009 
LA FABRICA DO BRASIL. Escola e família: instituições em conflito. 2001. Disponível em: <www1.folha.uol.com.br/ folha/ dimenstein/ sonosso/ pesquisa\%20s\%F3\%20nosso.ppt>. Acesso em: 10 out. 2002.

LA TAILLE, Y . A indisciplina e o sentimento de vergonha. In: AQUINO, J. G. (O rg.). Indisciplina na escola: alternativas teóricas e práticas. São Paulo: Summus, 1996. p. 9-24.

LA TAILlE, Y. Autonomia e identidade. Revista Criança do Professor de Educação Infantil, Brasília, v. 35, p. 16-18, 2001.

LEME, M. I. S. Educação: o rompimento possível do círculo vicioso da violência. In: MALUF, M. R. (O rg.). Psicologia educacional: questões contemporâneas. São Paulo: Casa do Psicólogo, 2004. p. 163-186.

Convivência, conflitos e educação nas escolas de São Paulo. São Paulo: ISME, 2006.

MORENO, M.; SASTRE, G. Resolução de conflitos e aprendizagem emocional. São Paulo: Moderna, 2002.

NAKAYAMA, A. M. A. Disciplina na escola: o que pensam os pais, professores e alunos de uma escola de 1ํo Grau. 1996. 239 f. D issertação (Mestrado em Psicologia Escolar e do D esenvolvimento Humano) - Universidade São Paulo, São Paulo, 1999.

PERE IRA, M. I. G. G. Emoções e conflitos: análise da dinâmica das interações numa classe de educação infantil. 1998. 209 f. Tese (D outorado em Educação) Faculdade de Educação, Universidade São Paulo, São Paulo, 1998.

PIAG ET, J. 0 julgamento moral na criança. São Paulo: Mestre Jou, 1932-1977.

PUIG, J. Democracia e participação escolar. São Paulo: Moderna, 2000.

Práticas morais: uma abordagem sociocultural da educação moral. São Paulo: Moderna, 2004.

TOGNETTA, L. R. P. A construção da solidariedade e a educação do sentimento na escola: uma proposta de trabalho com as virtudes numa visão construtivista. Campinas: Mercado de Letras, 2003.

TOG NETTA, L. R. P.; VINHA, T. P. Quando a escola é democrática: um olhar sobre a prática das regras e assembléias na escola. Campinas: Mercado de Letras, 2007.

Rev. Diálogo Educ., Curitiba, v. 9, n. 28, p. 525-540, set./ dez. 2009 
VASCONCELOS, M. S. Indisciplina no contexto escolar: estudo a partir de representações de professores do ensino fundamental e médio. Apresentação de trabalho. Florianópolis: ANPEP, 2005.

VINHA, T. P. 0 educadore a moralidade infantil numa visão construtivista. Campinas: Mercado de Letras, 2000.

O s conflitos interpessoais na relação educativa. 2003. 427 f. Tese (D outorado em Educação) - Faculdade de Educação, Universidade Estadual de Campinas, Campinas, 2003.

VinYAmATA, E. La resolución de conflitos. Cuadernos de Pedagogia, Barcelona, n. 246, p. 89-91, 1999.

Recebido: 26/ 02/ 2009

Received: 02/ 26/ 2009

Aprovado: $12 / 03 / 2009$

A pproved: 03/ 12/ 2009

Revisado: 16/ 09/ 2009

Reviewed: 09/ 16/ 2009

Rev. Diálogo Educ., Curitiba, v. 9, n. 28, p. 525-540, set./ dez. 2009 